\title{
Exhaled nitric oxide helps discriminating asthmatic children with and without positive specific IgE to aeroallergens
}

\author{
Li-Ching Fang, ${ }^{1}$ Shyh-Dar Shyur, ${ }^{1,2}$ Jen-Yu Wang, ${ }^{3}$ Yu-Hsuan Kao, ${ }^{1}$ Chien-Hui Yang, ${ }^{1}$ Yu-Ting Yu ${ }^{1}$
}

\begin{abstract}
Background: Aeroallergen sensitization may predict higher fractional exhaled nitric oxide (FeNO) levels.

Objective: We evaluate cut-off values of FeNO in asthmatic children with and without positive specific immunoglobulin $\mathrm{E}$ (IgE) to at least one of 5 aeroallergens (Dermatophagoides pteronyssinus, Dermatophagoides farinae, cat, dog, and cockroach).

Methods: 564 patients with asthma and allergic rhinitis (AR) aged 5 to 18 years were enrolled into two groups. Sensitized group included 378 children with positive IgE to at least one of 5 inhaled allergens. Non-sensitized group included 186 children. Pulmonary function tests, FeNO, eosinophil counts, and IgE levels were examined.

Patients were divided into preschool age (5 6 years old), elementary school children (7 11 years old) and adolescents (12 18 years old).

Results: In preschool children, FeNO $\geq 15.5$ ppb differentiates between non-sensitized and sensitized groups. (sensitivity 54.3\%; specificity 87.5\%; positive predictive value (PPV) $86.2 \%$; negative predictive value (NPV) $57.1 \%$; area under receiver operating characteristic curve (AUC) 0.72) Among elementary school children, the cut-off value of FeNO $\geq 19.5$ ppb showed sensitivity 66.4\%; specificity 85.8\%; PPV 90.5\%; NPV 55.7\%; AUC 0.81. In adolescents, FeNO $\geq 27.5$ ppb showed sensitivity $60.2 \%$; specificity $85.4 \%$; PPV 91.2\%; NPV 46.1\%; AUC 0.76.
\end{abstract}

Conclusion: In asthmatic children, aeroallergen sensitization appears to contribute to higher FeNO levels than those not sensitized. Cut-off values of FeNO which well discriminate asthmatic children with and without aeroallergen sensitization should be chose according to different ages.

Keywords: aeroallergen, allergic rhinitis, asthma, children, exhaled nitric oxide

\section{From:}

${ }^{1}$ Department of Pediatrics, Mackay Memorial Hospital, Taipei, Taiwan

${ }^{2}$ School of Medicine, Mackay Medical College, New Taipei City, Taiwan

Department of Dermatology, Mackay memorial hospital, Taipei,

Taiwan

\section{Background}

Asthma is a common allergic disease globally. One study showed approximately 32 percent of preschool children in the United States and Europe had recurrent episodes of troublesome cough, wheeze or breathlessness. ${ }^{1}$ In Taiwan, $20.4 \%$ of children aged 3 to 6 years experienced asthma like symptoms while attending kindergarten. ${ }^{2}$

Aeroallergen and indoor allergen (cat, dog and dust mites) sensitization may make FeNO levels higher and asthma more severe. ${ }^{3-5}$ In Taiwan, from 1997 to 1999, inhalant allerges are the major allergens. House dust mites,

\section{Corresponding author:}

Shyh-Dar Shyur

Department of Pediatrics, Mackay Memorial Hospital,

Mackay Medical College

\#92, Chungshan North Road, Section 2, Taipei, TAIWAN

E-mail: abc4540@gmail.com

Dermatophagoides pteronyssinus (Dp) and Dermatophagoides farinae (Df), cockroaches, feathers, and dog dander showed the highest incidence in the 7- to 12 -year-old group. ${ }^{6} \mathrm{Dp}$ and Df sensitization were correlated to higher asthma severity. ${ }^{7}$ Sensitization to animal dander and cockroach were also reported as causes of severe and uncontrolled asthma. ${ }^{5}$

Fraction of exhaled nitric oxide (FeNO) is considered as a convenient and non-invasive method to monitor airway inflammation. Persuasive evidence exists that levels of nitric oxide (NO) are increased in association with airway 
inflammation and are decreased by anti-inflammatory treatments. ${ }^{8}$ Some studies have shown that FeNO may be helpful in asthma control and guiding treatment policies. ${ }^{9,10}$ In asthmatic patients, FeNO levels are correlated with other markers of eosinophil recruitment, which are detected in blood, sputum, bronchoalveolar lavage fluid and bronchial biopsy samples. ${ }^{11}$ From previous studies, allergic sensitization seems an important factor affecting FeNO levels. ${ }^{12}$ However, the relationship of FeNO levels and inhaled allergens sensitization is not well known in Taiwanese asthmatic children.

The primary objective of this study was to find out the differences between asthmatic children with and without positive specific IgE to at least one of 5 inhaled allergens, (Dp, Df, cat, dog, and cockroach). The parameters studied included lung function test, FeNO levels, serum eosinophil level, and serum IgE level.

\section{Materials and Methods \\ Subjects and study design}

This was a retrospective medical records study from Jan. 2009 to Dec. 2013. A total of 564 patients aged 5 to 18 years were enrolled in this study (43.26\% females, $56.74 \%$ males, mean age $9.67 \pm 3.04$ years). There were 564 consecutively enrolled eligible cases (diagnosed as asthma and AR) from outpatients' clinic in Mackay Memorial Hospital (MMH), in Taipei, Taiwan. Asthma and AR were diagnosed based on criteria according to Global Initiative for Asthma (GINA) guideline, and Allergic Rhinitis and Its Impact on Asthma (ARIA) guideline. The clinical asthma severity of all subjects ranged from intermittent to mild persistent asthma. All subjects were inhaled corticosteroid -naïve patients.

Patients were divided into two groups. Non-sensitized group included 186 children with asthma and AR without positive specific IgE to any of the 5 inhaled allergens (including Dp, Df, cat, dog and cockroach). Sensitized group included 378 children with asthma, AR and positive specific $\operatorname{IgE}$ to at least one of 5 inhaled allergens.

For the physiological difference, we divided all subjects into three age groups, including preschool age children (5 to 6 years old), elementary school children (7 to 11 years old) and adolescents (12 to 18 years old). (Figure 1)
Exclusion criteria included rhinosinusitis, airway anomalies, malignant neoplasm, autoimmune diseases, foreign body aspiration, cystic fibrosis, gastroesophageal reflux, bronchiectasis, tuberculosis, bronchopulmonary dysplasia, and active smoking, asthma with acute attack within recent one month, having systemic steroid within recent two weeks, upper respiratory infection within recent two weeks.

\section{White blood cells and eosinophil}

White blood cell counts were obtained, and peripheral blood eosinophil counts were counted on a UniCel DxH 800 analyzer (Beckman Coulter, Miami, FL).

\section{Total IgE and specific IgE}

Serum specific IgE levels were measured by a fluorescent enzyme immunoassay (ImmunoCAP system, Phadia AB, Uppsala, Sweden). Serum total IgE levels were analyzed employing the IMMULITE 2000 (Siemens Healthcare Diagnostics Inc., Deerfield, IL, USA). The specific IgE levels to each aeroallergen (Dp, Df, cat, dog, cockroach) were classified as class 1 , class 2 , class 3 , class 4 , class 5 , and class 6 . Class 1 is the mildest, and class 6 is the most severe.

\section{Measurement of FeNO}

All subjects completed FeNO measurements. FeNO levels were measured by using chemiluminescence detection methods (NIOX MINO, Aerocrine, Solna, Sweden) according to the American Thoracic Society/European Respiratory Society (ATS/ERS) recommendations. ${ }^{13}$ Subjects exhaled at a constant flow rate of $50 \mathrm{~mL} / \mathrm{s}$ and sat in an upright position. Exhalation time was 6 to 10 seconds with an analysis time of 2 minute. Measurement was taken before other pulmonary function tests. The time when patients were subjected to FeNO study was between nine o'clock to twelve o'clock in the morning. All subjects were told to avoid nitrate- rich foods (ex. sausage, cured meat, pickled food) and strenuous exercise two hours before FeNO measurements. All subjects were also told not to have bronchodilators one day before FeNO measurements.

\section{Pulmonary function test}

535 children successfully completed the spirometric maneuvers. All subjects followed the ATS/ERS standards. ${ }^{14,15}$

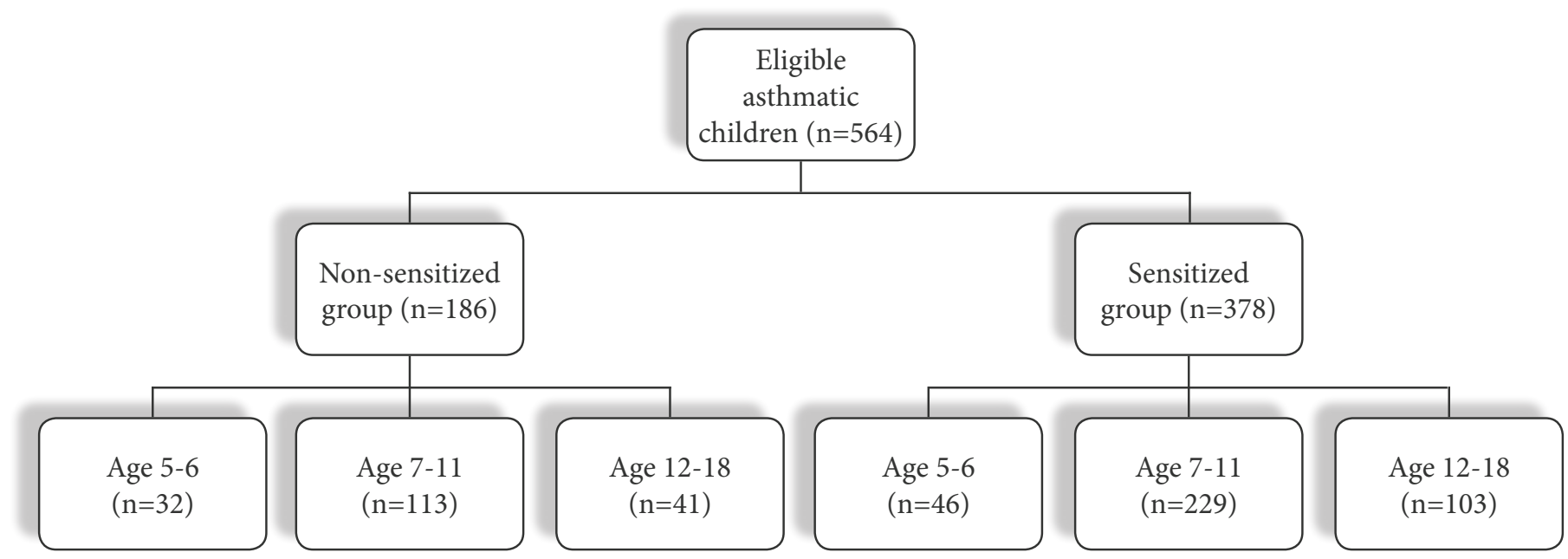


Forced expiratory volume in 1 second (FEV1), forced vital capacity (FVC) and forced expiratory flow 25-75\% (FEF 2575) were measured by a pulmonary function test unit named of Vmax Encore 22 (VIASYS Healthcare, CareFusion, San Diego, CA, USA). "ERS 1993 Update + Zapletal" was used for predicted values in Vmax encore system. ${ }^{16} \mathrm{FEV}_{1} / \mathrm{FVC}$ is the ratio of $\mathrm{FEV}_{1}$ to $\mathrm{FVC}$.

\section{Statistical analysis}

The primary analysis focused on the evaluation among asthmatic children with and without aeroallergen sensitization and the exploration of the cut-off values of FeNO levels between the two groups.

Comparisons of independent samples (aeroallergen positive vs. aeroallergen negative) were assessed with Mann-Whitney $U$ test and student's t test for continuous variables.

Univariate and multivariate linear regression models were used to analyze factors affecting FeNO. A receiver operating characteristic (ROC) curve was constructed to find out the proper cut-off values of FeNO levels for discriminating aeroallergen positive and aeroallergen negative groups. AUC was used to assess the result of ROC curve. Sensitivity, specificity, PPV and NPV for the corresponding cut-off values of FeNO were calculated.

Statistical significance was determined at the 0.05 levels for all tests. All statistical analyses were performed using software (SPSS Inc, SPSS for windows, version 12.0, Chicago, IL).

\section{Results}

\section{Subject characteristics}

A total of 564 children aged 5 to 18 years were enrolled in this study (43.26\% females, $56.74 \%$ males, mean age $9.67 \pm 3.04$ years). Of the 564 children with asthma and AR, 94.86\% (535 patients) completed pulmonary function tests.

We've analyzed FeNO of these 564 patients with univariate and multivariate linear regression models. The involved contributing factors for FeNO included age, gender, height, weight, aeroallergen positivity, eosinophil counts, serum total IgE, FEV1, FEV1/FVC, and FEF 25-75. The statistically significant factors of FeNO were age $(P=0.035)$ and aeroallergen positivity $(P=0.001)$. Therefore we categorized the children into sensitized group and non-sensitized group. And we separate the two groups into three ages groups.

Children in non-sensitized group had mean age of $9.28 \pm$ 2.83 years old, mean body height of $135.56 \pm 18.52$ centimeter, mean body weight of $34.96 \pm 14.93$ kilogram, and a male to female ratio of 1:1.09 (89/97). Children in sensitized group had mean age of $9.86 \pm 3.14$ years old, mean body height of $138.61 \pm 16.52$ centimeter, mean body weight of $36.45 \pm 14.20$ kilogram, and a male to female ration of 1 to $0.64(231 / 147)$. The differences in height and weight between two groups were insignificant. (Table 1) Among the three subgroups (preschool age, elementary school children and adolescents), there is no significant difference in age between non-sensitized and sensitized group.

\section{Spirometric measurements}

Aeroallergen-positive group seem to have worse small
Table 1.

\begin{tabular}{|llll}
\hline & $\begin{array}{l}\text { Aeroallergen } \\
\text { negative } \\
\text { (non-sensitized } \\
\text { group) }\end{array}$ & $\begin{array}{l}\text { Aeroallergen } \\
\text { positive } \\
\text { (sensitized } \\
\text { group) }\end{array}$ & P value \\
\hline Patient numbers & 186 & 378 & \\
\hline Age (years old) & $9.28 \pm 2.83$ & $9.86 \pm 3.14$ & 0.027 \\
\hline $\begin{array}{l}\text { Gender } \\
\text { (male/female) }\end{array}$ & $1: 1.09$ & $1: 0.64$ & \\
\hline Height (cm) & $135.56 \pm 18.52$ & $138.61 \pm 16.52$ & 0.057 \\
\hline Weight (kg) & $34.96 \pm 14.93$ & $36.45 \pm 14.20$ & 0.256 \\
\hline $\begin{array}{l}\text { Eosinophil counts } \\
\text { (cell/ul) }\end{array}$ & $85.54 \pm 136.58$ & $223.44 \pm 296.09$ & 0.000 \\
\hline Total IgE (IU/mL) & $61.70 \pm 83.63$ & $703.51 \pm 998.70$ & 0.000 \\
\hline $\begin{array}{l}\text { FEF 25 to 75 (\% } \\
\text { predicted) }\end{array}$ & $55.99 \pm 17.14$ & $53.86 \pm 19.72$ & 0.201 \\
\hline FEV1 (\% predicted) & $99.16 \pm 19.96$ & $97.86 \pm 50.68$ & 0.671 \\
\hline FEV1/FVC & $90.63 \pm 7.59$ & $88.28 \pm 7.71$ & 0.001 \\
\hline FeNO (ppb) & $15.54 \pm 10.87$ & $30.58 \pm 20.70$ & 0.000 \\
\hline
\end{tabular}

Non-sensitized group: aeroallergen negative children with asthma and allergic rhinitis, total 186 people

Sensitized group: aeroallergen positive children with asthma and allergic rhinitis, total 378 people

The values were presented as mean \pm standard deviation.

Abbreviations:

$\mathrm{FEF}=$ forced expiratory flow

$\mathrm{FEV} 1=$ forced expiratory volume in 1 second

$\mathrm{FVC}=$ forced vital capacity

$\mathrm{FeNO}=$ fraction of exhaled nitric oxide; p.p.b. $=$ parts per billion

airway and large airway functions than aeroallergen-negative group, although some lung function parameters such as FEF 25-75 and FEV1 are not statistically different. In patients completing the spirometric maneuver, sensitized patients had lower FEF $25-75$ (53.86 \pm 19.72 vs. $55.99 \pm 17.14, p=0.201)$, lower FEV1 (97.86 $\pm 50.68 \%$ vs. $99.16 \pm 19.96 \%, p=0.671)$ and lower $\mathrm{FEV}_{1} / \mathrm{FVC}(88.28 \pm 7.71$ vs. $90.63 \pm 7.59, p=0.001)$ than non-sensitized patients. (Table 1)

\section{Blood test results}

For blood test results, sensitized group had higher eosinophil counts compared to non-sensitized group $(223.44 \pm 296.09$ vs. $85.54 \pm 136.58, p=0.000)$, and higher serum levels of total $\operatorname{IgE}(703.51 \pm 998.70$ vs. $61.70 \pm 83.63, p=0.000)$ (Table 1)

\section{Exhaled nitric oxide}

Considering the possible influence of gender on FeNO, we use Mann-Whitney U test to compare the FeNO levels between male and female. Within non-sensitized group, there is no significant difference in FeNO levels between male and female $(16.65 \pm 12.86$ vs. $14.52 \pm 8.58, p=0.305)$. We also got the same result in the sensitized group (male vs. female $=31.76 \pm 20.84$ vs. $28.72 \pm 20.40, p=0.109$ ). Therefore, the difference in gender between two groups is insignificant in this study. 
In children aged 5 to 18 years, aeroallergen-positive children had higher FeNO levels than aeroallergen-negative children (30.58 \pm 20.70 vs. $15.54 \pm 10.87, P=0.000$ ). (Table 1 ) The optimal cut-off value of FeNO levels between the two groups is 20.5 ppb (AUC [95\%CI] 0.78 [0.74-0.82]; sensitivity 62.4\%; specificity $85.5 \%$; PPV 89.7\%; NPV 52.8\%). The positive likelihood ration ( $\mathrm{LR}+)$ is 4.30 . And the negative likelihood ration (LR-) was 0.44. (Table 3; Figure 2A) The pretest probability for aeroallergen sensitized children in our study was $67 \%$. At the cut-off value of $20.5 \mathrm{ppb}$, we got a post-test probability of $89.7 \%$. Therefore, children with FeNO levels $\geq$ $20.5 \mathrm{ppb}$ had $89.7 \%$ post-test probability to have aeroallergen sensitization in our study.

In preschool age children, sensitized group had higher FeNO

Table 2. Comparison of FeNO values between different sensitization and age groups

\begin{tabular}{llll}
\hline \multicolumn{3}{c}{ FeNO $(\mathbf{p p b})($ mean \pm SD) } \\
\hline & $\begin{array}{l}\text { Aeroallergen } \\
\text { negative } \\
\text { (non-sensitized } \\
\text { group) }\end{array}$ & $\begin{array}{l}\text { Aeroallergen } \\
\text { positive } \\
\text { (sensitized } \\
\text { group) }\end{array}$ & P value \\
\hline $\begin{array}{l}5 \sim 6 \text { years old } \\
(\mathrm{N}=78)\end{array}$ & $11.53 \pm 3.90$ & $17.44 \pm 8.08$ & 0.001 \\
\hline $\begin{array}{l}7 \sim 11 \text { years old } \\
(\mathrm{N}=342)\end{array}$ & $14.80 \pm 8.86$ & $29.75 \pm 18.49$ & 0.000 \\
\hline $\begin{array}{l}12 \sim 18 \text { years old } \\
(\mathrm{N}=144)\end{array}$ & $20.71 \pm 16.52$ & $38.29 \pm 25.51$ & 0.000 \\
\hline
\end{tabular}

\section{Abbreviations:}

$\mathrm{FeNO}=$ fraction of exhaled nitric oxide; p.p.b. $=$ parts per billion

$\mathrm{SD}=$ standard deviation

$\mathrm{N}=$ patient number

A

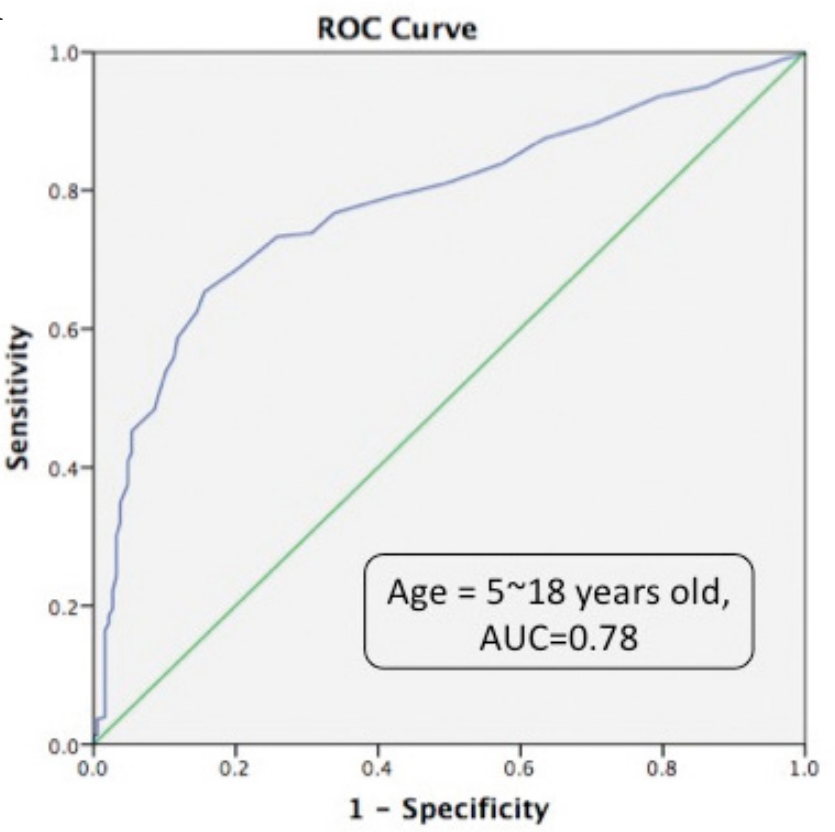

levels than non-sensitized group ( $17.44 \pm 8.08$ vs. $11.53 \pm 3.90$, $P=0.001)$. (Table 2) The proper cut-off levels of FeNO (15.5 $\mathrm{ppb}$ ) between sensitized group and non-sensitized group were chose according to the Youden's index (sensitivity vs. specificity $=54.3 \%$ vs. $87.5 \%$, respectively) ${ }^{17}$. Therefore, FeNO $\geq 15.5 \mathrm{ppb}$ can help differentiating the two groups in children aged 5 to 6 years with well PPV and NPV (86.2\% vs. $57.1 \%$, respectively), The AUC, LR+, LR- were 0.72 (0.61-0.83), 4.34 and 0.52, respectively. (Table 3; Figure 2B) The pretest probability of sensitized children in preschool age of our study was $59 \%$. If the FeNO was greater than or equal to $15.5 \mathrm{ppb}$, the post-test probability would be $86.2 \%$.

Table 3.

\begin{tabular}{lcccc}
\hline Age (years old) & $\mathbf{5 \sim 1 8}$ & $\mathbf{5 \sim 6}$ & $\mathbf{7 \sim 1 1}$ & $\mathbf{1 2 \sim 1 8}$ \\
\hline $\begin{array}{l}\text { Cut-off value of FeNO (ppb) between } \\
\text { non-sensitized group and sensitized } \\
\text { group }\end{array}$ & 20.5 & 15.5 & 19.5 & 27.5 \\
\hline AUC & 0.78 & 0.72 & 0.81 & 0.76 \\
Sensitivity (\%) & 62.4 & 54.3 & 66.4 & 60.2 \\
Specificity (\%) & 85.5 & 87.5 & 85.8 & 85.4 \\
PPV (\%) & 89.7 & 86.2 & 90.5 & 91.2 \\
\hline NPV (\%) & 52.8 & 57.1 & 55.7 & 46.1 \\
\hline LR (+) & 4.30 & 4.34 & 4.67 & 4.12 \\
\hline LR (-) & 0.44 & 0.52 & 0.39 & 0.47 \\
\hline
\end{tabular}

\section{Abbreviations:}

ROC curve $=$ Receiver operating characteristic curve

$\mathrm{AUC}=$ Area under the curve of ROC

$\mathrm{PPV}=$ Positive predictive value; NPV $=$ Negative predictive value LR $(+)=$ Likelihood ration $(+)$; LR (-) = Likelihood ration $(-)$

B

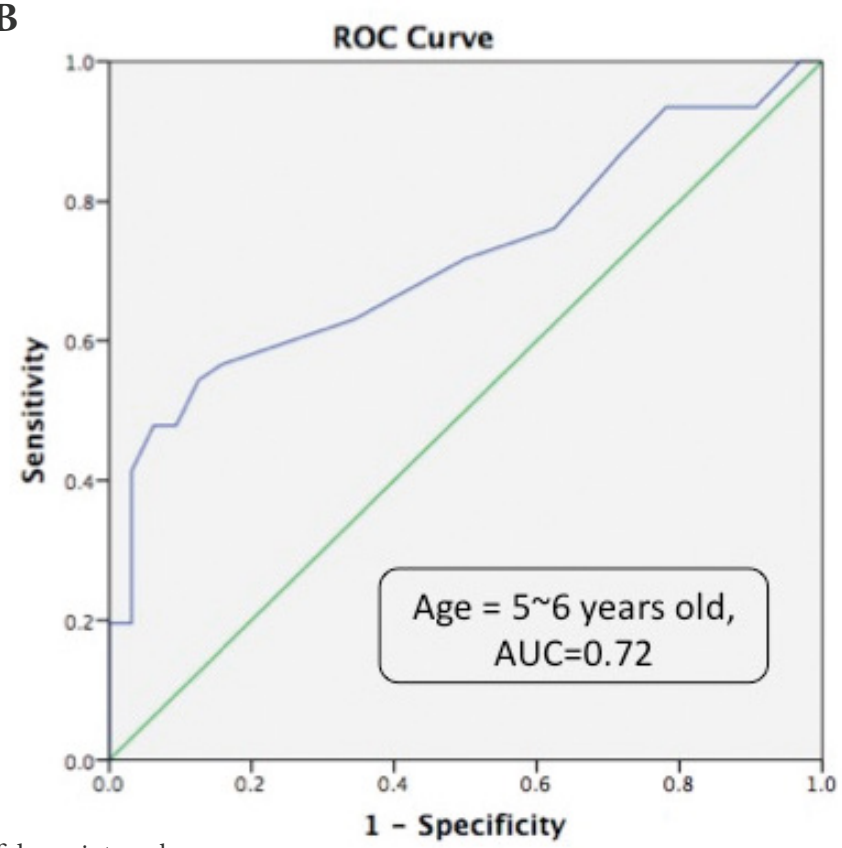

Abbreviation: CI: Confidence interval

Figure 2. Receiver operating characteristic (ROC) curves were constructed in different age groups. (A) Children aged 5 to 18 years (FeNO $\geq 20.5 \mathrm{ppb}$, area under the ROC curve[AUC][95\%CI]0.78[0.74-0.82]); (B) Children aged 5 to 6 years (FeNO $\geq 15.5$ ppb, AUC 0.72[0.61-0.83]); 
C

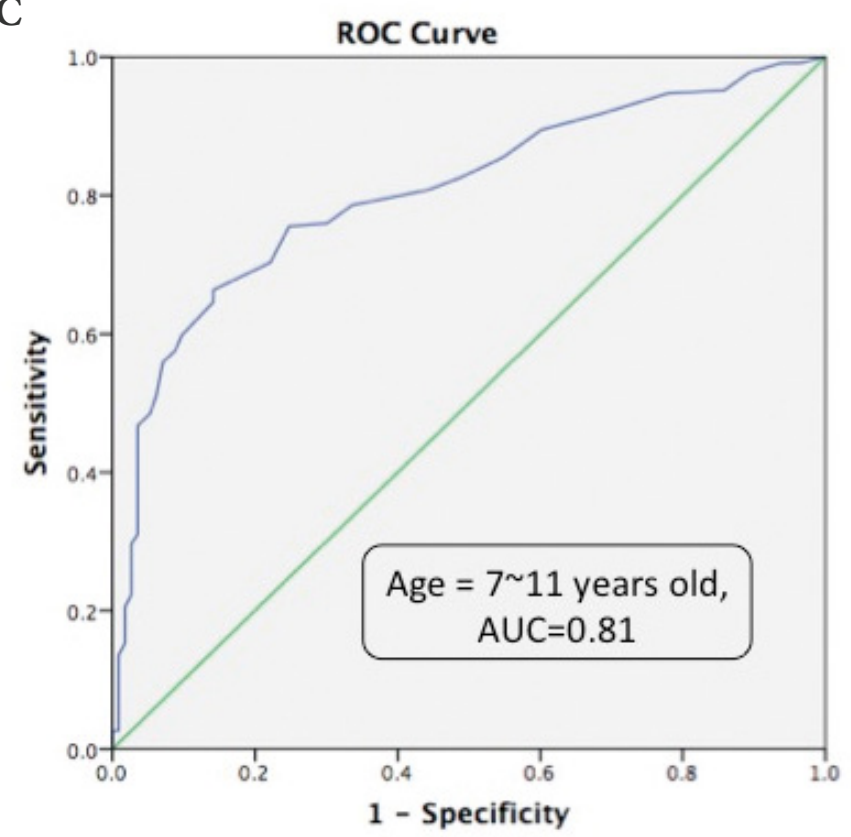

D

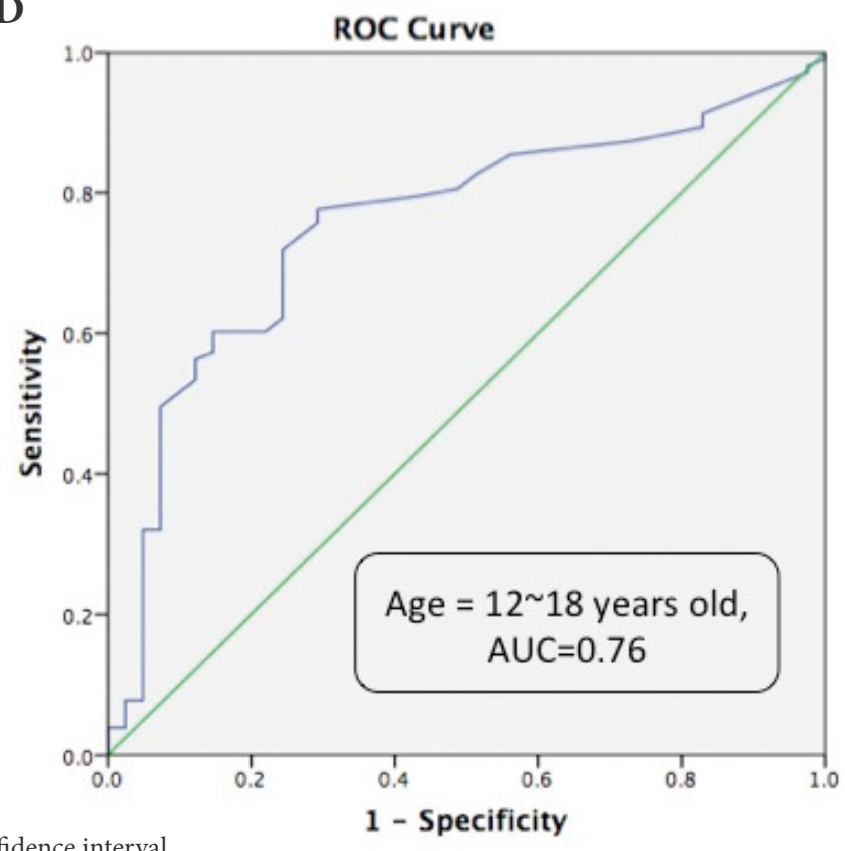

Figure 2. (Continued) (C) Children aged 7 to 11 years (FeNO $\geq 19.5$ ppb, AUC 0.81[0.76-0.85]); (D) Children aged 12 to 18 years $(\mathrm{FeNO} \geq 27.5 \mathrm{ppb}, \mathrm{AUC} 0.76[0.67-0.84])$

In children aged 7 to 11 years, sensitized group had significant higher FeNO levels than non-sensitized group $(29.75 \pm 18.49$ vs. $14.80 \pm 8.86, P=0.000)$. (Table 2$)$ The cut-off level of FeNO $\geq 19.5 \mathrm{ppb}$ could have a high discriminatory ability between sensitized and non-sensitized group with AUC $0.81(0.76-0.85)$. The sensitivity, specificity, PPV and NPV were $66.4 \%, 85.8 \%, 90.5 \%$ and $55.7 \%$, respectively. The LR+ and LR- were 4.67 and 0.39 . Pretest and post-test probability in this age were $67 \%$ and $90.5 \%$. (Table 3; Figure 2C)

In adolescents, the sensitized group had higher FeNO levels than non-sensitized group ( $38.29 \pm 25.51$ vs. $20.71 \pm 16.52$, $P=0.000$ ). (Table 2) The cut-off value of $\mathrm{FeNO} \geq 27.5 \mathrm{ppb}$ gave a good PPV of $91.2 \%$. The sensitivity, specificity, AUC, NPV, LR+, and LR- were 60.2\%, 85.4\%, 0.76 (0.67-0.84), 46.1\%, 4.12 , and 0.47 , respectively. (Table 3; Figure 2D) The pretest probability of aeroallergen sensitization in adolescents was $71.5 \%$. With a cut-off value of FeNO $\geq 27.5 \mathrm{ppb}$, we had a high post-test probability of $91.2 \%$.

\section{Discussion}

Asthma is an inflammatory airway disease, encompassing heterogeneous pathological condition, and characterized by different phenotypes/endotypes related to specific biomarkers. Immunoglobulin E plays a key role in some allergic disease and asthma. From our data, as shown in Table 1, asthmatic children with IgE sensitization to aeroallergen had poorer lung function test results, higher FeNO levels, and higher eosinophil counts compared to those without sensitization. The findings in our study are compatible with the concept that aeroallergen sensitization is associated with airway inflammation in asthmatic children, which is also supported in a Korean study showing that sensitization to house dust mite is strongly associated with the development of airway inflammation in asthmatic population. ${ }^{21}$
Allergen exposure seems to be an important determinant for FeNO levels in IgE-sensitized children. ${ }^{4}$ Besides, FeNO is considered to be associated with allergic disease. ${ }^{12,18}$ We explore the influence of allergic sensitization in FeNO levels among asthmatic children. Inhaled allergen had been reported to have impact on FeNO. ${ }^{12,18}$ In Southern Europe, mite sensitization is the main determinant of increased FeNO levels, while in Northern Europe pet allergens (cat and dog) have the greatest impact on FeNO levels. ${ }^{19}$ In Asian, one study found that $\operatorname{IgE}$ sensitization to mites, animals, cockroaches, respectively, is significantly associated with elevated FeNO levels in children. ${ }^{20}$ Sordillo et al. considered that FeNO is highest in children sensitized and exposed to dust mite. Allergies to mites, pets (dog and cat), and pests were all associated with FeNO. ${ }^{21}$ In this study, we choose five most common inhaled allergens including Dp, Df, cat, dog, and cockroach for discussion. The sensitization prevalence of the five allergens we choose was reported of Dp (94.5\%), Df (92.7\%), cat (3.6\%), dog (7.3\%), and cockroach $(21.8 \%)$ in children with atopic disorders in Taiwan. ${ }^{22}$ We found that sensitized group (children with positive IgE response to at least one of the five allergens) had higher levels of FeNO than non-sensitized group in all age groups.

The pathological basis is suggested in a Swedish study showing that IgE sensitization and the degree of allergic sensitization were related to the increase in airway $\mathrm{NO}$ transfer factor and the increase in NO concentration in the airway wall. ${ }^{22}$

From previous studies, FeNO can be influenced by many factors not just allergic diseases, but also age, medications, nitrate-rich diet, atopic disease, respiratory disease such as cystic fibrosis, tobacco smoking, alcohol consumption, and exercise. ${ }^{8,10,23}$ American thoracic society also suggested that age should be accounted for a factor affecting FeNO in 
children younger than 12 years old. ${ }^{10}$ Although one study reported that FeNO was not associated with age in healthy Korean children. $^{24}$ However, FeNO levels of healthy Thais were influenced by age. ${ }^{25}$ In Taiwan, another study reported age as an independent determinant of FeNO levels, which is compatible to our finding. ${ }^{12}$ Considering the physiologic differences during children growth, we split all subjects into three age groups, including preschool age, elementary school children, and adolescents.

A high FeNO value may indicate active eosinophil mediated airway inflammation and the likelihood of deteriorations in asthma control. ${ }^{26}$ Inhaled allergens were reported of contributing to higher FeNO levels and more responsible for severe asthma. ${ }^{5,20}$ However, the optimal cut-off levels of FeNO for discriminating asthmatic children with and without allergen sensitization for clinical use remain a question.

From our study, we found cut-off values from different age groups. The cut-off point of $20.5 \mathrm{ppb}$ in children aged 5 to 18 years has fair specificity $(85.5 \%)$ and high PPV (89.7\%), but moderate sensitivity (62.4\%) and NPV (52.8\%). The pretest probability for allergic sensitization was $67 \%$ according to the prevalence in asthmatic children aged 5 to 18 years in our study. The LR+ of cut-off value at $20.5 \mathrm{ppb}$ was 4.30 , resulting in a post-test probability of $89.7 \%$ with allergic sensitization prevalence. Comparing with other study in Taiwan, the prevalence of Dp, Df were both reported of $91.2 \%$ in children with bronchial asthma and AR. ${ }^{22}$ If those children have FeNO $\geq 20.5 \mathrm{ppb}$, the post-test probability of aeroallergen sensitization will be $97.8 \%$. We also suggested other proper cut-off values in three different age groups. From our data, for preschool age children with FeNO $\geq 15.5 \mathrm{ppb}$, the post-test probability would be $86.2 \%$, which is $27.2 \%$ higher than the pre-test probability. For elementary school children having FeNO $\geq 19.5 \mathrm{ppb}$, the post-test probability would be $90.5 \%$, which increased the test probability by $27.2 \%$. In adolescents, with $\mathrm{FeNO} \geq 27.5 \mathrm{ppb}$, the post-test probability was $91.2 \%$, with an increased test probability by $19.7 \%$. However, the mean level of FeNO in non-sensitized group of children aged 12 to 18 years was $20.71 \mathrm{ppb}$, thus the calculated cut-off value of $20.5 \mathrm{ppb}$ in children aged 5 to 18 years cannot well discriminate half of the non-sensitized group in this age group. (Table 2) Therefore, to discriminate aeroallergen sensitization in asthmatic children, we strongly recommend clinicians to choose cut-off values of FeNO based on proper age groups.

Although FeNO cut-off values were reported in various clinical conditions and age populations, our study showed comparable FeNO cut-off values and specifically discriminate the sensitized/non-sensitized groups in asthmatic children with different age groups. The American Thoracic Society suggested that in children with asthma, FeNO $<20 \mathrm{ppb}$ implies good adherence to anti-inflammatory therapy or non-eosinophilic asthma. ${ }^{10}$ In Spain, Alvarez-Puebla et al. reported FeNO $<21 \mathrm{ppb}$ has been used to rule out airway eosinophilia in corticosteroid-naïve patients. ${ }^{27}$ While one study showed that the titers of specific IgE antibody to Dp were found to be more strongly correlated with the rate of FeNO higher than $21 \mathrm{ppb}$ in asthmatic children aged 8 to 16 years. ${ }^{28}$ Sachs-Olsen found in their birth cohort that a FeNO cut-off value of $20.4 \mathrm{ppb}$ in 10 years old children had a high specificity (97\%), but low sensitivity (41\%) and a LR+ of 16.1 for current allergic asthma. ${ }^{29}$

FeNO not only reflects airway eosinophilic inflammation. It's also a tool helping to decide who might benefit from steroid treatment. ${ }^{30}$ Furthermore, FeNO can be used to help clinicians adjusting the therapeutic policy. ${ }^{10}$ From our data, asthmatic children tend to have higher FeNO levels and worse lung function test results, if they are aeroallergen sensitized. Therefore, a good FeNO cut-off value may help differentiating the sensitized group. From other studies, sensitization to mites, animal dander, and cockroaches were correlated to higher asthma severity. ${ }^{5,7}$ Thus, the cut-off values of FeNO in different age groups in this study might help clinicians making decisions and avoiding unnecessary corticosteroid therapy. Besides, performing FeNO to discriminate asthmatic children with or without allergic sensitization is non-invasive and easy. Other than serum IgE test or skin prick test, children can avoid blood drawing or fear.

The measurement of exhaled nitric oxide is helpful in clinical practice. The exhaled NO may be used to help diagnosing asthma, ${ }^{31,32}$ monitoring clinical therapy for asthma control. ${ }^{33-35}$ Further studies of different populations are needed for FeNO to be a more elite guide and monitor of therapy.

\section{Conclusion}

In summary, we found that aeroallergen sensitization is associated with significant elevation of FeNO levels in asthmatic children, most likely due to an increased airway inflammation. Appropriate cut-off values of FeNO levels should be chose according to different ages to differentiate aeroallergen sensitization and non-sensitization in asthmatic children.

\section{Conflicts of interest}

All authors declare that they have no any conflicts of interest.

\section{Author contribution}

Dr. Jen-Yu Wang contributed to the statistical analysis and data analysis, drafting of manuscript.

Dr. Shyh-Dar Shyur and Dr. Li-Ching Fang contributed to drafting of manuscript, data analysis and interpretation.

Dr.Yu-Hsuan Kao, Dr. Chien-Hui Yang, and Dr.Yu-Ting Yu contributed to data collections.

\section{References}

1. Bisgaard H, Szefler S. Prevalence of asthma-like symptoms in young children. Pediatr Pulmonol. 2007;42:723-8.

2. Yeh KW, Ou LS, Yao TC, Chen LC, Lee WI, Huang JL. Prevalence and risk factors for early presentation of asthma among preschool children in Taiwan. Asian Pac J Allergy Immunol. 2011;29:120-6.

3. Barreto M, Villa MP, Martella S, Ronchetti F, Darder MT, Falasca C, et al. Exhaled nitric oxide in asthmatic and non-asthmatic children: influence of type of allergen sensitization and exposure to tobacco smoke. Pediatr Allergy Immunol. 2001;12:247-56.

4. Janson C, Kalm-Stephens P, Foucard T, Norback D, Alving K, Nordvall SL. Exhaled nitric oxide levels in school children in relation to IgE sensitisation and window pane condensation. Respir Med. 2005;99:1015-21.

5. Lombardi C, Savi E, Ridolo E, Passalacqua G, Canonica GW. Is allergic sensitization relevant in severe asthma? Which allergens may be culprit? World Allergy Organ J. 2017;10:2

6. Lee CS, Tang RB, Chung RL. The evaluation of allergens and allergic diseases in children. J Microbiol Immunol Infect. 2000;33:227-32. 
7. Li J, Huang Y, Lin X, Zhao D, Tan G, Wu J, et al. Influence of degree of specific allergic sensitivity on severity of rhinitis and asthma in Chinese allergic patients. Respir Res. 2011;12:95.

8. Barnes PJ, Kharitonov SA. Exhaled nitric oxide: a new lung function test. Thorax. 1996;51:233-7.

9. Ricciardolo FL, Sorbello V, Ciprandi G. A pathophysiological approach for FeNO: A biomarker for asthma. Allergol Immunopathol (Madr). 2015;43(6):609-16.

10. Dweik RA, Boggs PB, Erzurum SC, Irvin CG, Leigh MW, Lundberg JO, et al. An official ATS clinical practice guideline: interpretation of exhaled nitric oxide levels (FENO) for clinical applications. Am J Respir Crit Care Med. 2011;184:602-15.

11. Choi BS, Kim KW, Lee YJ, Baek J, Park HB, Kim YH, et al. Exhaled nitric oxide is associated with allergic inflammation in children. J Korean Med Sci. 2011;26:1265-9.

12. Yao TC, Ou LS, Lee WI, Yeh KW, Chen LC, Huang JL, et al. Exhaled nitric oxide discriminates children with and without allergic sensitization in a population-based study. Clin Exp Allergy. 2011;41:556-64.

13. ATS/ERS recommendations for standardized procedures for the online and offline measurement of exhaled lower respiratory nitric oxide and nasal nitric oxide, 2005. Am J Respir Crit Care Med. 2005;171:912-30.

14. Beydon N, Davis SD, Lombardi E, Allen JL, Arets HG, Aurora P, et al. An official American Thoracic Society/European Respiratory Society statement: pulmonary function testing in preschool children. Am J Respir Crit Care Med. 2007;175:1304-45.

15. Miller MR, Crapo R, Hankinson J, Brusasco V, Burgos F, Casaburi R, et al. General considerations for lung function testing. Eur Respir J. 2005;26: 153-61.

16. Zapletal A, Samanek M, Paul T. Lung function in children and adolescents: Methods, reference values. In: Herzog H, editors. Progress in Respiratory Research. New York: Karger; 1987. p. 114-218.

17. Youden WJ. Index for rating diagnostic tests. Cancer. 1950;3:32-5.

18. Patelis A, Gunnbjornsdottir M, Malinovschi A, Matsson P, Onell A, Hogman M, et al. Population-based study of multiplexed IgE sensitization in relation to asthma, exhaled nitric oxide, and bronchial responsiveness. J Allergy Clin Immunol. 2012;130:397-402 e2.

19. Malinovschi A, Janson C, Holmkvist T, Norback D, Merilainen P, Hogman M. IgE sensitisation in relation to flow-independent nitric oxide exchange parameters. Respir Res. 2006;7:92.

20. Yao TC, Tsai HJ, Tu YL, Chang SW, Hua MC, Liao SL, et al. Multiplexed immunoglobulin $\mathrm{E}$ sensitization in relation to exhaled nitric oxide in a population sample of children. Allergy. 2014;69:678-82.

21. Sordillo JE, Webb T, Kwan D, Kamel J, Hoffman E, Milton DK, et al. Allergen exposure modifies the relation of sensitization to fraction of exhaled nitric oxide levels in children at risk for allergy and asthma. J Allergy Clin Immunol. 2011;127:1165-72 e5
22. Huang HW, Lue KH, Wong RH, Sun HL, Sheu JN, Lu KH. Distribution of allergens in children with different atopic disorders in central Taiwan. Acta Paediatr Taiwan. 2006;47:127-34.

23. Bahna SL. Should exhaled nitric oxide measurement be part of routine asthma management? Ann Allergy Asthma Immunol. 2012;109:289-91.

24. Cho HJ, Jung YH, Yang SI, Lee E, Kim HY, Seo JH, et al. Reference values and determinants of fractional concentration of exhaled nitric oxide in healthy children. Allergy Asthma Immunol Res. 2014;6:169-74.

25. Suksawat Y, Pacharn P, Jirapongsananuruk O, Visitsunthorn N Determination of fractional exhaled nitric oxide (FENO) reference values in healthy Thai population. Asian Pac J Allergy Immunol[Preprint]. 2016[cited 2017 Jul 12]:[5 p.]. Available from: http://apjai-journal.org/ wp-content/uploads/2017/06/AP0840.pdf

26. Yang S, Park J, Lee YK, Kim H, Hahn YS. Association of longitudinal fractional exhaled nitric oxide measurements with asthma control in atopic children. Respir Med. 2015;109:572-9.

27. Alvarez-Puebla MJ, Olaguibel Rivera JM, Almudevar E, Echegoyen AA, de Esteban Chocarro B, Cambra K. Cutoff point for exhaled nitric oxide corresponding to 3\% sputum eosinophils. J Investig Allergol Clin Immunol. 2015;25:107-11.

28. Lee YK, Yang S, Park J, Kim H, Hahn YS. House dust mite-specific immunoglobulin $\mathrm{E}$ and longitudinal exhaled nitric oxide measurements in children with atopic asthma. Korean J Pediatr. 2015;58:89-95.

29. Sachs-Olsen C, Lodrup Carlsen KC, Mowinckel P, Haland G, Devulapalli CS, Munthe-Kaas MC, et al. Diagnostic value of exhaled nitric oxide in childhood asthma and allergy. Pediatr Allergy Immunol. 2010;21:e213-21.

30. Smith AD, Cowan JO, Brassett KP, Filsell S, McLachlan C, Monti-Sheehan G, et al. Exhaled nitric oxide: a predictor of steroid response. Am J Respir Crit Care Med. 2005;172:453-9.

31. Smith AD, Cowan JO, Filsell S, McLachlan C, Monti-Sheehan G, Jackson P, et al. Diagnosing asthma: comparisons between exhaled nitric oxide measurements and conventional tests. Am J Respir Crit Care Med 2004;169:473-8.

32. Dupont LJ, Demedts MG, Verleden GM. Prospective evaluation of the validity of exhaled nitric oxide for the diagnosis of asthma. Chest. 2003;123:751-6.

33. Pijnenburg MW, Hofhuis W, Hop WC, De Jongste JC. Exhaled nitric oxide predicts asthma relapse in children with clinical asthma remission. Thorax. 2005;60:215-8.

34. Sippel JM, Holden WE, Tilles SA, O'Hollaren M, Cook J, Thukkani N, et al. Exhaled nitric oxide levels correlate with measures of disease control in asthma. J Allergy Clin Immunol. 2000;106:645-50.

35. Cowan DC, Taylor DR, Peterson LE, Cowan JO, Palmay R, Williamson A, et al. Biomarker-based asthma phenotypes of corticosteroid response. J Allergy Clin Immunol. 2015;135:877-83 e1. 